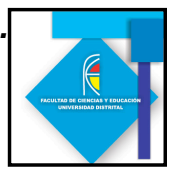

\title{
LA NOCIÓN DE MARCO Y SISTEMA DE REFERENCIA PARA LA ENSEÑANZA DE LA RELATIVIDAD DEL MOVIMIENTO EN LA FÍSICA CLÁSICA
}

\author{
THE CONCEPT OF REFERENCE FRAMEWORK AND SYSTEM \\ FOR TEACHING \\ RELATIVITY OF MOTION IN CLASSICAL PHYSICS
}

Oscar Fernando Gallo Aconcha ${ }^{1}$

\begin{abstract}
Resumen
La introducción de la enseñanza de la física moderna y en particular de la relatividad del movimiento en la educación media se ha convertido en la última década en una preocupación para investigadores de la didáctica de la física y maestros. Con esta propuesta se pretende mostrar la importancia que tienen las nociones de marco y sistema de referencia en la relatividad clásica y de cómo influyen e la enseñanza de la relatividad del movimiento.

En muchos casos la comprensión de algunos conceptos no ha sido lograda de la mejor manera, generando falencias a la hora de analizar fenómenos y enfrentar la validez de proposiciones teóricas que dan cuenta de los mismos; esto ocurre, en particular cuando se enseñan temas referentes a la relatividad del movimiento.

El trabajo se limitara a mostrar como las nociones de movimiento, espacio y cuerpo están íntimamente ligadas a las nociones de marco y sistema de referencia y de cómo estos últimos están muy lejos de una simple definición.
\end{abstract}

Palabras clave: Marco de referencia, Sistema de referencia, Relatividad del movimiento, movimiento, espacio, cuerpo, enseñanza, Física.

\begin{abstract}
The introduction of the teaching of modern physics and particular the relativity of motion in the secondary education has become in the last decade a concern for teaching researchers and physics teachers. This proposal aims show the importance of the concepts and framework frame of reference in classical relativity and how influence and teaching of relativity of motion.

In many cases the understanding of some concepts has not been achieved in the best manner, causing failures when analyzing phenomena and deal whit the validity of theoretical propositions that account for the same, this is particularly true when teaching subjects related to relativity of motion.
\end{abstract}

\footnotetext{
${ }^{1}$ Universidad Pedagógica Nacional.

Oscar1076@hotmail.com
} 


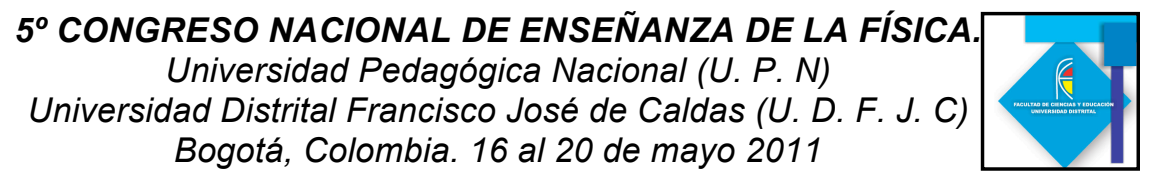

The work is limited to show how the notions of movement, space and body are inextricably linked to notions of context and reference latter are very far from a simple definition.

Keywords: Frame of reference, reference system, relativity of motion, movement, space, body, teaching physics.

\section{La relatividad del movimiento, una mirada histórica}

La relatividad es una parte importante de la física moderna, que ha proporcionado grandes avances en la ciencia y también ha tenido una gran influencia cultural. Por eso es pertinente saber sus inicios y por que ha sido de gran importancia desde los orígenes de la física.

Para ello partimos de la siguiente pregunta: ¿Qué es el movimiento? Para aproximarnos un poco a la idea de movimiento y que esta a su vez nos muestre un poco de como surgió la relatividad clásica es necesario partir de 3 visiones. En primer lugar se encuentra la visión Aristotélica, la cual se presenta de la siguiente manera:

"la física aristotélica no se limita a expresar, en su lenguaje, el hecho del sentido común que acabamos de evocar: lo refleja, y la distinción de los movimientos en $<<$ naturales $>>$ y <<violentos>> se enmarca en una concepción general de la realidad física, concepción cuyas piezas maestras parecen ser: a) la creencia en la existencia de <<naturalezas >> bien determinadas, y b) la creencia en la existencia de un cosmos, es decir, la creencia en la existencia de principios de orden en virtud de los cuales el conjunto de los entes reales forma un todo (naturalmente) bien ordenado."

Este fragmento nos presenta la relación entre las naturalezas y el cosmos, es decir, que existen elementos constituyentes que definen la naturaleza de los cuerpos (tierra, agua, aire, fuego) y que a su vez se convierten en principios fundamentales mediante los cuales podemos definir un orden en el cosmos. Por ejemplo, nosotros sabemos que una piedra pertenece a la tierra, por lo tanto, su movimiento en la tierra será natural porque pertenece a este, pero si nosotros ahora lanzamos esa piedra hacia arriba decimos que ese cuerpo es violentado porque lo sacamos de su lugar natural y lo enviamos a un lugar que no le corresponde. Además hace una separación entre las características de los cuerpos, los que pertenecían a los elementos de la tierra y el agua eran cuerpos graves y los que estaban compuestos por aire y fuego eran los cuerpos leves.

La segunda visión es la Galileana y en ella Galileo considera que no existen cuerpos en reposo, que siempre ellos tienden por naturaleza volver a algún lugar en particular. También muestra la existencia de los cuerpos graves en donde los leves desaparecen por completo, además define el movimiento como un estado-relación donde la visión Aristotélica sobre el cosmos se desvanece y da pasó a la universalidad, que serian las leyes que rigen las naturalezas. De igual forma surge la pesantez o la gravedad como una fuente de movimiento que es la única propiedad natural que poseen los cuerpos y que por lo tanto origina un movimiento natural hacia abajo. 


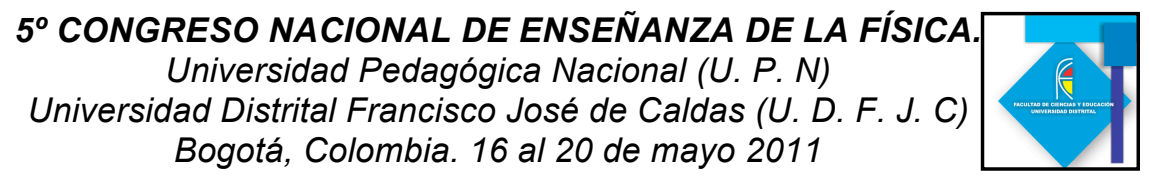

En la tercera visión aparece Newton donde empieza a darle una visión diferente a los conceptos de espacio, movimiento y lugar entre otros, por ejemplo, su "escolio" al inicio de sus Principia dice:

"Hasta aquí he expuesto las definiciones de las palabras menos conocidas, explicando el sentido en el que deberían entenderse para lo sucesivo. Tiempo, espacio, lugar y movimiento son palabras conocidísimas para todos. Es de observar, con todo, que el vulgo sólo concibe esas cantidades partiendo de la relación que guardan con las cosas sensibles. Y de ello surgen ciertos prejuicios, para cuya remoción será conveniente distinguir allí entre lo absoluto y lo relativo, lo verdadero y lo aparente, lo matemático y lo vulgar."

Desde esta perspectiva y para superar esta aparente contradicción, los movimientos sensibles, es decir, el movimiento de un cuerpo respecto a otro son pensados como la diferencia entre el movimiento absoluto del cuerpo en cuestión y el movimiento absoluto del cuerpo de referencia y sólo se puede dar cuenta de esta diferencia; de modo que si no la hay se hablaría de reposo respecto al cuerpo. En este contexto uno puede preguntarse si todos los movimientos sensibles son verdaderos o no, o dicho en otras palabras, si no hay lugares de referencia privilegiados.

Ahora surgen las siguientes preguntas respecto estas visiones: Siempre decimos que un cuerpo se encuentra en movimiento si este cambia de posición pero ¿Cómo sabemos que realmente un cuerpo se esta moviendo? Es claro que al rotar un cuerpo se puede decir que no cambia de lugar, considerar que no hay tal cambio de lugar es entonces ¿la rotación un movimiento?

A partir de la caracterización del movimiento se deja ver que las ideas de movimiento están ligadas a las nociones de espacio y cuerpo lo que me permitirá mostrar sus aportes al surgimiento de la relatividad del movimiento.

\section{Referencias Bibliográficas}

Koyré, A. (1980). Estudios Galileanos. México: siglo veintiuno editores

Bondi, H. (1980). Relativity and common sense. A new approach to Einstein. New York: Dover Publications, Inc.

Newton, I. (1982). Principios Matemáticos de la Filosofía Natural. Madrid: Editora Nacional 